\section{Status and Ecological Effects of the World's Largest Carnivores}

William J. Ripple, ${ }^{*}$ James A. Estes, Robert L. Beschta, Christopher C. Wilmers, Euan G. Ritchie, Mark Hebblewhite, Joel Berger, Bodil Elmhagen, Mike Letnic, Michael P. Nelson, Oswald J. Schmitz, Douglas W. Smith, Arian D. Wallach, Aaron J. Wirsing

Background: The largest terrestrial species in the order Carnivora are wide-ranging and rare because of their positions at the top of food webs. They are some of the world's most admired mammals and, ironically, some of the most imperiled. Most have experienced substantial population declines and range contractions throughout the world during the past two centuries. Because of the high metabolic demands that come with endothermy and large body size, these carnivores often require large prey and expansive habitats. These food requirements and wide-ranging behavior often bring them into conflict with humans and livestock. This, in addition to human intolerance, renders them vulnerable to extinction. Large carnivores face enormous threats that have caused massive declines in their populations and geographic ranges, including habitat loss and degradation, persecution, utilization, and depletion of prey. We highlight how these threats can affect the conservation status and ecological roles of this planet's 31 largest carnivores.

Advances: Based on empirical studies, trophic cascades have been documented for 7 of the 31 largest mammalian carnivores (not including pinnipeds). For each of these species (see figure), human actions have both caused declines and contributed to recovery, providing "natural experiments" for quantifying their effects on food-web and community structure. Large carnivores deliver economic and ecosystem services via direct and indirect pathways that help maintain mammal, avian, invertebrate, and herpetofauna abundance or richness. Further, they affect other ecosystem processes and conditions, such as scavenger subsidies, disease dynamics, carbon storage, stream morphology, and crop production. The maintenance or recovery of ecologically effective densities of large carnivores is an important tool for maintaining the structure and function of diverse ecosystems.

Outlook: Current ecological knowledge indicates that large carnivores are necessary for the maintenance of biodiversity and ecosystem function. Human actions cannot fully replace the role of large carnivores. Additionally, the future of increasing human resource demands and changing climate will affect biodiversity and ecosystem resiliency. These facts, combined with the importance of resilient ecosystems, indicate that large carnivores and their habitats should be maintained and restored wherever possible. Preventing the extinction of these species and the loss of their irreplaceable ecological function and importance will require novel, bold, and deliberate actions. We propose a Global Large Carnivore Initiative to coordinate local, national, and international research, conservation, and policy.
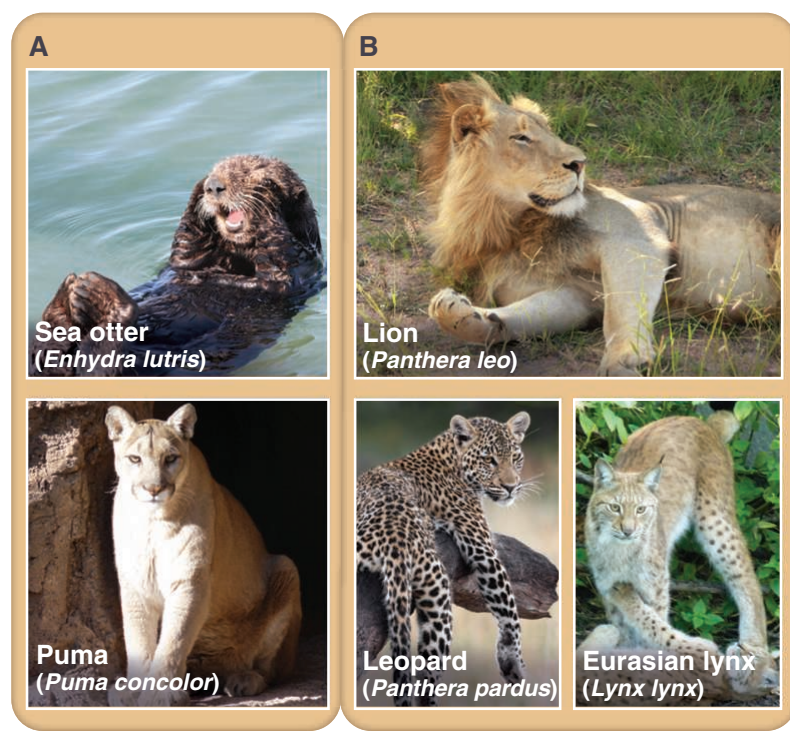

READ THE FULL ARTICLE ONLINE http://dx.doi.org/10.1126/science.1241484

Cite this article as W. ]. Ripple et al., Science 343, 1241484 (2014). DOI: $10.1126 /$ science. 1241484

\section{ARTICLE OUTLINE}

\section{Ecological Effects of Large Carnivores}

Ecosystem and Economic Services

Anthropogenic Impacts

Climate Change

Outlook

\section{A Final Word}

\section{SUPPLEMENTARY MATERIALS}

Figs. $\mathrm{S} 1$ to $\mathrm{S} 4$

Tables S1 to S3

\section{ADDITIONAL RESOURCES}

"Lords of nature: Living in a land of great predators"; www.youtube.com/ watch?v=PagO3gmwmA0

George Monbiot, TED "For more wonder, rewild the world"; www.youtube.com/ watch? $\mathrm{v}=8 \mathrm{rZzH} \mathrm{kpyPkc}$

Trophic Cascades Program, www.cof.orst.edu/ cascades/

Large Carnivore Initiative for Europe, www.lcie. org/Home.aspx

\section{RELATED ITEMS IN SCIENCE}

]. A. Estes et al., "Trophic downgrading of planet Earth." Science 333, 301-306 (2011).

Ecologically important carnivores. Seven species of large carnivores with documented ecological effects involving (A) "tri-trophic cascades" from large carnivores to prey to plants, (B) "mesopredator cascades" from large carnivores to mesopredators to prey of mesopredators, and (C) both tri-trophic and mesopredator cascades. [Photo credits: sea otter (N. Smith), puma (W. Ripple), lion (K. Abley), leopard (A. Dey), Eurasian lynx (B. Elmhagen), dingo (A. McNab), gray wolf (D. Mclaughlin)]

The list of author affiliations is available in the full article online.

*Corresponding author. E-mail: bill.ripple@oregonstate.edu 


\section{Status and Ecological Effects of the World's Largest Carnivores}

\author{
William J. Ripple, ${ }^{1 *}$ ]ames A. Estes, ${ }^{2}$ Robert L. Beschta, ${ }^{1}$ Christopher C. Wilmers, ${ }^{3}$ \\ Euan G. Ritchie, ${ }^{4}$ Mark Hebblewhite, ${ }^{5}$ Joel Berger, ${ }^{6}$ Bodil Elmhagen, ${ }^{7}$ \\ Mike Letnic, ${ }^{8}$ Michael P. Nelson, ${ }^{1}$ Oswald J. Schmitz, ${ }^{9}$ Douglas W. Smith, ${ }^{10}$ \\ Arian D. Wallach, ${ }^{11}$ Aaron ]. Wirsing ${ }^{12}$
}

Large carnivores face serious threats and are experiencing massive declines in their populations and geographic ranges around the world. We highlight how these threats have affected the conservation status and ecological functioning of the 31 largest mammalian carnivores on Earth. Consistent with theory, empirical studies increasingly show that large carnivores have substantial effects on the structure and function of diverse ecosystems. Significant cascading trophic interactions, mediated by their prey or sympatric mesopredators, arise when some of these carnivores are extirpated from or repatriated to ecosystems. Unexpected effects of trophic cascades on various taxa and processes include changes to bird, mammal, invertebrate, and herpetofauna abundance or richness; subsidies to scavengers; altered disease dynamics; carbon sequestration; modified stream morphology; and crop damage. Promoting tolerance and coexistence with large carnivores is a crucial societal challenge that will ultimately determine the fate of Earth's largest carnivores and all that depends upon them, including humans.

\section{$\mathrm{T}$} he order Carnivora consists of 245 terrestrial species inhabiting nearly every major habitat on Earth (1). These mammalian species, which we call carnivores, are generally unified by a shared heritage of subsisting largely on other animals and are naturally rare because of their position at the top of the food web. These are also some of the world's most revered and iconic species. Ironically, they are also some of the most threatened. During the previous two centuries, many carnivores have experienced substantial population declines, geographic range contractions, and fragmentation of their habitat $(2,3)$.

\footnotetext{
${ }^{1}$ Trophic Cascades Program, Department of Forest Ecosystems and Society, Oregon State University, Corvallis, OR 97331, USA. ${ }^{2}$ Department of Ecology and Evolutionary Biology, University of California, Santa Cruz, CA 95060, USA. ${ }^{3}$ Center for Integrated Spatial Research, Department of Environmental Studies, University of California, Santa Cruz, CA 95064, USA. ${ }^{4}$ Centre for Integrative Ecology and School of Life and Environmental Sciences, Deakin University, Burwood, Victoria 3125, Australia. ${ }^{5}$ Wildlife Biology Program, Department of Ecosystem and Conservation Sciences, College of Forestry and Conservation, University of Montana, Missoula MT, 59812, USA, and Department of Biodiversity and Molecular Ecology, Research and Innovation Centre, Fondazione Edmund Mach, Via Mach 1 38010 San Michele all'Adige (TN), Italy. ${ }^{6}$ Department of Organismic Biology and Ecology, University of Montana, Missoula MT 59812, and Wildlife Conservation Society, Bronx, NY 10460 USA. ${ }^{7}$ Department of Zoology, Stockholm University, SE-106 91 Stockholm, Sweden. ${ }^{8}$ School of Biological, Earth and Environmental Sciences, University of New South Wales, Sydney, New South Wales 2052, Australia. ${ }^{9}$ School of Forestry and Environmental Studies, Yale University, New Haven, CT 06511, USA

${ }^{10}$ Yellowstone Center for Resources, Yellowstone National Park, Post Office Box 168, Mammoth, WY 82190, USA. ${ }^{11}$ School of Marine and Tropical Biology, James Cook University, Townsville, Queensland 4811, Australia. ${ }^{12}$ School of Environmental and Forest Sciences, University of Washington, Seattle, WA 98195 , USA.

*Corresponding author. E-mail: bill.ripple@oregonstate.edu
}

Carnivores of various sizes play an important role in regulating ecosystems (4-7). These roles, moreover, may not be redundant among carnivore species, because the strength and nature of their impacts are influenced by factors such as the carnivore's size, metabolic demands, density, sociality, and hunting tactics. The larger carnivores especially tend to have large energetic constraints, slow life histories, and low population densities and roam widely in search of larger prey $(8-10)$. This conflation of low population densities and reproductive rates with high food requirements and wide-ranging behavior, bringing them into conflict with humans and livestock, is what makes them vulnerable and poorly able to respond to persecution.

Large carnivores can exert ecological effects despite existing at low densities (11), but persecution can affect their social structure and influence their ecological role (12). Classically, the effects of large carnivores are thought to extend down the food web to herbivores and to plants, but we are learning that their cascading influences propagate broadly to other species as mediated by their controlling effects on mesocarnivores $(4,13,14)$. Large carnivores have the dual role of potentially limiting both large herbivores through predation and mesocarnivores through intraguild competition, thus structuring ecosystems along multiple food-web pathways. Together, these controls influence the nature and strength of ecosystem functioning. What makes the conservation of large carnivores exceptionally important, therefore, is both their vulnerability to extinction and their ability to structure ecosystems. With this in mind, our focus here is on the largest carnivores.

We review the conservation status and ecological effects of the 31 largest (average adult body masses $\geq 15 \mathrm{~kg}$ ) species of Carnivora (not including pinnipeds). Although most of these species are obligate meat eaters, some are omnivorous and one is herbivorous (Table 1). The remaining 214 carnivore species with body masses $<15 \mathrm{~kg}$ are not considered here, but we acknowledge they also can play important and varied roles in communities $(4,13)$. The 31 largest carnivores belong to five families: Canidae, Felidae, Mustelidae, Ursidae, and Hyaenidae. They generally have small population sizes (Fig. 1 and table S1), often due to high levels of range loss (Table 1). Many of these species (61\%) are listed by the International Union for the Conservation of Nature (IUCN) as threatened (vulnerable, endangered, or critically endangered) and are at risk of local or total extinction. Most (77\%) are undergoing continuing population declines (Table 1). Estimates of range contractions for 17 of the 31 species revealed that they currently occupy on average only $47 \%$ (minimum $<1 \%$, maximum $73 \%$ ) of their historical ranges (Table 1). These range losses can result in local population extinctions, which have implications for the maintenance of ecosystem and socioeconomic services. Thus, many of these species are gradually disappearing just as we are beginning to understand and appreciate their roles in ecosystems and the many societal benefits that accrue from their preservation $(5,15)$.

We report our current understanding of the substantial ecological roles large-carnivore species play in ecosystems and how their population declines, extirpations, and recoveries stand to influence ecological communities and ecosystems across the globe. We further consider how those roles may change as environmental conditions become altered when humans cause habitat loss and climate change. We end by addressing the outlook for the future and the looming uncertainties motivating an urgent need for more research on carnivore interactions in food webs and the conservation of these species.

\section{Ecological Effects of Large Carnivores}

Seven of the 31 species of large carnivores are associated with documented trophic cascades. Therefore, we focus on these seven species with analysis and discussion. Each of the seven species is well studied in comparison to other large carnivores (fig. S2). In all cases, these seven species of large carnivores clearly have cascading influences on ecological communities and ecosystems. We assessed the general strength of these effects using available data to calculate the $\log _{10}\left(X_{\mathrm{a}} / X_{\mathrm{p}}\right)$ effect magnitudes, where $X_{\mathrm{a}}$ and $X_{\mathrm{p}}$ are the values for the response variables with the large-carnivore species absent and present, respectively [for methods, see (6)]. The effect magnitude of large-carnivore removal on the abundance of prey, plants, and mesopredators ranged from -2.3 to 2.3 (Fig. 2). These are considered large effects. For example, an effect size of 2 or -2 represents a difference of two orders of magnitude (100 times) in the effect 
between when carnivores are absent as compared to present. These values also rank relatively high when compared to a meta-analysis of 114 case studies of predators from both aquatic and terrestrial systems, where effects, expressed in $\log _{10}$ ratios, ranged from -0.3 to 1.0 (16). With the exception of the sea otter, all of the aquatic and terrestrial predators included in that study were $\leq 2 \mathrm{~kg}$ in body mass, suggesting a potential link between carnivore size and ecological influence. Below we provide a brief synthesis for each of the seven large-carnivore species. Following these species accounts is a general discussion of other large-carnivore species, for which less is known about their ecological effects.

\section{Lions and Leopards}

The African lion (Panthera leo) occupies 17\% of its historical range and is listed as vulnerable by the IUCN. Its abundance has declined dramatically in recent decades because of habitat loss and indiscriminate killing in defense of humans and livestock (17). The leopard (Panthera pardus) is near threatened and occupies $65 \%$ of its historical range. When sympatric, lions and leopards exert control on mesopredators. In West Africa, olive baboons (Papio anubis) increased in abundance at rates most closely correlated with declines in these apex predators relative to seven other environmental variables that might explain baboon abundance and range occupancy (18). Increases in baboons correlated with accelerated declines in small ungulates and primates. Among large mammals, baboons pose the greatest threat to livestock and crops and they use many of the same sources of animal protein and plant foods as humans in sub-Saharan Africa. In some areas, baboon raids in agricultural fields require fami- lies to keep children out of school so they can help guard planted crops (18).

\section{Dingoes}

The dingo (Canis dingo), thought to have arrived in Australia around 5000 years ago (19), became the sole remaining mammalian apex predator on the continent after the extinction of the Tasmanian tiger (Thylacinus cynocephalus). With European settlement, dingo populations have been affected across the continent, notably by the erection of a 5500-km dingo-proof fence designed to keep dingoes out of Australia's major sheep-grazing region. The presence and absence of dingoes on either side of the fence, along with variation in dingo management practices among properties, has produced a continental-scale experiment. The most significant and well-understood effects of dingoes are in the control of populations of native
Table 1. Large-carnivore species list, body mass (in kilograms), diet, endangerment status, population trend, and percent of historical range occupied. Body masses are from Gittleman (15), Mammalian Species Accounts, and the Animal Diversity Web. Diet categories are from
Hunter (1) as follows: $M$, meat eater; V, vegetation and/or fruit eater; 0 , omnivore. Species status and trend are from the IUCN Red List (16): LC, least concern; NT, near threatened; VU, vulnerable; EN, endangered; CR, critically endangered.

\section{Family/species* \\ Common name \\ Mass, diet IUCN status (trend) $\%$ of historical range \\ Reference for $\%$ of historical range}

\begin{tabular}{l} 
Canidae \\
Canis lupus \\
Canis rufus \\
Chrysocyon brachyurus \\
Lycaon pictus \\
Cuon alpinus \\
Canis dingo \\
Canis simensis \\
Felidae \\
Panthera tigris \\
Panthera leo \\
Panthera onca \\
Acinonyx jubatus \\
Panthera pardus \\
Puma concolor \\
Panthera uncia \\
Neofelis nebulosa \\
Neofelis diardi \\
Lynx lynx \\
Mustelidae \\
Enhydra lutris \\
Pteronura brasilliensis \\
Aonyx capensis \\
Ursidae \\
Ursus maritimus \\
Ursus arctus \\
Ailuropoda melanoleuca \\
Ursus americanus \\
Tremarctos ornatus \\
Ursus thibetanus \\
Melursus ursinus \\
Helarctos malayanus \\
Crocuta crocuta \\
Hyaena brunnea \\
Hyaena hyaena \\
\hline
\end{tabular}

\begin{tabular}{|c|c|c|}
\hline Gray wolf & $33, M$ & LC (stable) \\
\hline Red wolf & $25, M$ & CR (increasing) \\
\hline Maned wolf & 23,0 & NT (unknown) \\
\hline African wild dog & $22, M$ & EN (decreasing) \\
\hline Dhole & $16, M$ & EN (decreasing) \\
\hline Dingo & $15, M$ & VU (decreasing) \\
\hline Ethiopian wolf & $15, M$ & EN (decreasing) \\
\hline Tiger & $161, M$ & EN (decreasing) \\
\hline Lion & $156, M$ & VU (decreasing) \\
\hline Jaguar & $87, M$ & NT (decreasing) \\
\hline Cheetah & $59, M$ & VU (decreasing) \\
\hline Leopard & $53, M$ & NT (decreasing) \\
\hline Puma & $52, M$ & LC (decreasing) \\
\hline Snow leopard & $33, M$ & EN (decreasing) \\
\hline Clouded leopard & $20, M$ & VU (decreasing) \\
\hline Sunda clouded leopard & $20, M$ & VU (decreasing) \\
\hline Eurasian lynx & $18, M$ & LC (stable) \\
\hline Sea otter & $28, M$ & EN (decreasing) \\
\hline Giant otter & $24, M$ & EN (decreasing) \\
\hline Cape clawless otter & $19, M$ & LC (stable) \\
\hline Polar bear & $365, M$ & VU (decreasing) \\
\hline Brown bear & 299,0 & LC (stable) \\
\hline Giant panda & $134, \mathrm{~V}$ & EN (decreasing) \\
\hline American black bear & 111,0 & LC (increasing) \\
\hline Andean black bear & 105,0 & VU (decreasing) \\
\hline Asiatic black bear & 104,0 & VU (decreasing) \\
\hline Sloth bear & 102,0 & VU (decreasing) \\
\hline Sun bear & 46,0 & VU (decreasing) \\
\hline Spotted hyena & $52, M$ & LC (decreasing) \\
\hline Brown hyena & 43,0 & NT (decreasing) \\
\hline Striped hyena & 27,0 & NT (decreasing) \\
\hline
\end{tabular}

\begin{tabular}{|c|c|}
\hline 67 & (1) \\
\hline$<1$ & (91) \\
\hline 68 & (2) \\
\hline 10 & (17) \\
\hline- & - \\
\hline 84 & (20) \\
\hline 2 & $(17)$ \\
\hline 18 & (3) \\
\hline 17 & (17) \\
\hline 57 & (3) \\
\hline 17 & (17) \\
\hline 65 & (3) \\
\hline 73 & (3) \\
\hline- & - \\
\hline- & - \\
\hline- & - \\
\hline- & - \\
\hline- & - \\
\hline- & - \\
\hline- & - \\
\hline- & - \\
\hline 68 & (3) \\
\hline- & - \\
\hline 59 & (35) \\
\hline- & - \\
\hline- & - \\
\hline- & - \\
\hline- & - \\
\hline 73 & (17) \\
\hline 62 & (17) \\
\hline 62 & (17) \\
\hline
\end{tabular}

*Changes to taxonomic status have influenced the number of species included in this group, and some less-known and taxonomically ambiguous carnivores may be missing from this analysis because they have yet to be listed by the IUCN. TCurrently incorporates the New Guinea singing dog, C. hallstromi, whose taxonomic and conservation status is yet to be elucidated. 
herbivores, introduced herbivores, and the exotic mesopredator the red fox (Vulpes vulpes). The suppression of these species by dingoes reduces total herbivory and predation pressure, in turn benefiting plant communities and smaller native prey $(12,14,20,21)$. The dingo's social stability and associated behavior are thought to be key to its ecological effectiveness (12). Overall, the suppression of dingoes has probably contributed to the endangerment and extinction of small marsupials and rodents over much of the continent $(21,22)$.

\section{Eurasian Lynx}

The Eurasian lynx (Lynx lynx) maintains an extensive distribution in eastern and northern Eurasia, but it has been extirpated from large parts of Western Europe (23). At the continental scale, the effects of lynx predation increase with harsh winter conditions $(23,24)$. Lynx may limit both prey (roe deer Capreolus capreolus) and mesocarnivore (red fox) abundance, so changes in lynx status may trigger cascading effects along two pathways, of which the mesocarnivore-mediated cascade is the more explored (25). The recent recovery and enhanced conservation protection of Eurasian lynx in Finland were accompanied by a decline in red fox abundance and a commensurate recovery in the abundance of forest grouse (Tetrao tetrix and T. urogallus) and mountain hare (Lepus timidus) $(7,25)$. Moreover, where lynx density had recovered to "ecologically effective" levels, the controlling effects of lynx on red foxes and prey increased with ecosystem pro- ductivity, indicating that the strength of predator control may vary as a function of the net primary productivity of the ecosystem $(26,27)$.

\section{Sea Otters}

Sea otters (Enhydra lutris) were hunted to nearextinction during the Pacific maritime fur trade in the 18th and 19th centuries (28). Sea otter populations are presently stable or increasing from about Kodiak Island eastward, deeply depleted [presumably because of killer whale predation (29)] from about Kodiak Island westward through the Aleutian archipelago, and largely recovered in Russia. The earlier recovery of these populations and the more recent decline of recovered populations in southwest Alaska (29) offer natural experiments to study the sea otter's influences on coastal ecosystems. The best-documented cascade of effects involves sea otters limiting herbivorous sea urchins and, in turn, enhancing the abundance and distribution of kelp and other fleshy macroalgae in coastal inshore ecosystems (Fig. 3A) (30). As sea otter populations recover and decline, shifts between the kelp-dominated and urchin-dominated conditions can be abrupt (31). Once reached, these different ecological states tend to persist (32) unless the system is pushed strongly to the other state by substantial increases or reductions in otter abundance. The follow-on effects of these shifts influence numerous other species and ecological processes in coastal ecosystems through three basic mechanisms: the creation of biogenic habitat (i.e., created by living

\begin{abstract}
Fig. 1. Worldwide population estimates of large-carnivore species. Error bars represent the low and high range of the estimates when available. Population estimates were not available for all species. Species ranges vary widely, and range sizes can have a strong influence on species population levels (table S1). Sources: Gray wolf (90), all other species IUCN (91).
\end{abstract}

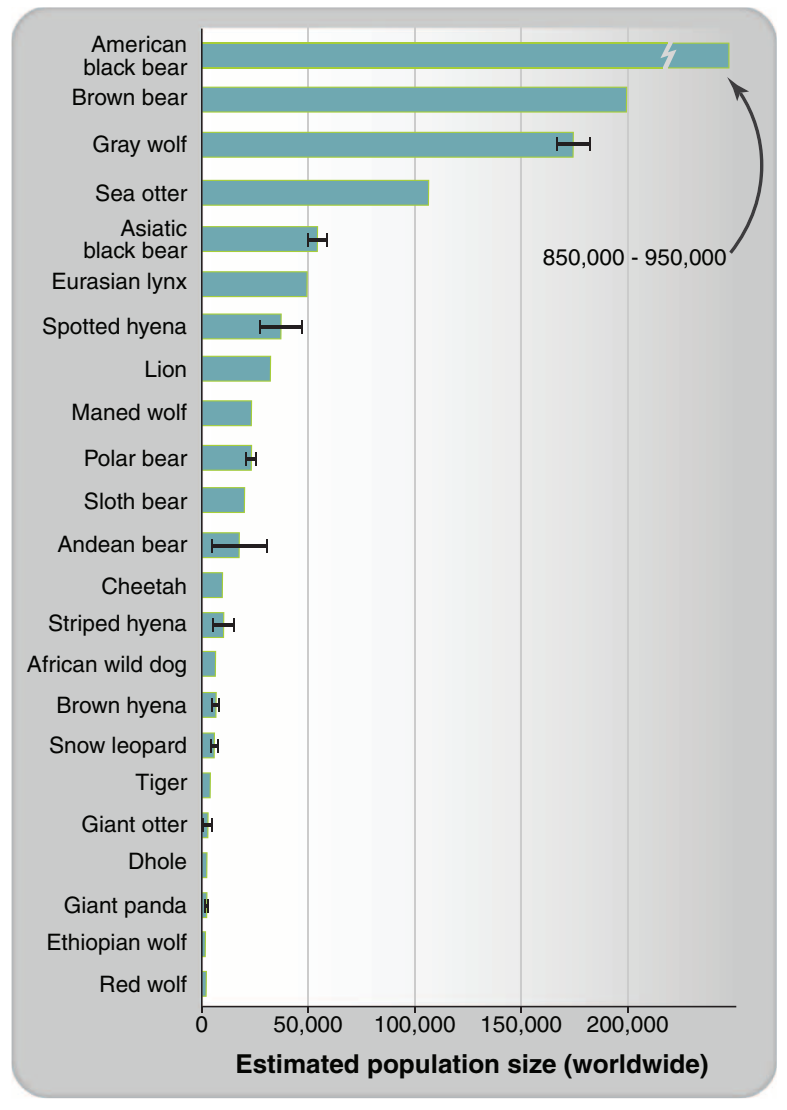

organisims), the enhancement of primary production, and the influence of kelp forests in dampening coastal waves and currents [reviewed in $(31)]$.

\section{Gray Wolves}

The gray wolf (Canis lupus) is one of the world's most widely distributed mammals and the most studied large carnivore (fig. S2). It has been extirpated from much of Western Europe, the United States, and Mexico, and its overall range has been reduced by approximately one-third because of persecution by humans and habitat fragmentation (1). In recent decades, wolf population declines have been arrested because of enhanced legal protection, reintroduction programs, and natural recolonization, resulting in population recoveries in portions of the Rocky Mountains, Great Lakes, and southwestern regions of North America, as well as in various parts of Europe. Other than humans, gray wolves, by virtue of their widespread geographic distribution, group hunting, and year-round activity, are the most important predator of cervids in the Northern Hemisphere (33). Predation by wolves with sympatric bears (Ursus spp.) generally limits cervid densities (33). In North America and Eurasia, cervid densities were, on average, nearly six times higher in areas without wolves than in areas with wolves (34). As early as the 1940s, cervid irruptions, after wolf and other predator declines, were first documented in various ecosystems of western North America (35). The shifts in plant communities consequent to the cascading effects of wolf extirpations and of recoveries have been found across a variety of areas of North America, representing a wide range of productivity (6). In Yellowstone National Park, wolves were reintroduced in 1995-1996, making this park one of the most predator-rich areas in North America. This reintroduction triggered various direct and indirect effects, as mediated by both mesopredators and cervid prey (Figs. 3B and 4).

\section{Pumas}

The range of the puma (Puma concolor) in the Western Hemisphere remains larger than that of any other terrestrial mammal, even though they have been extirpated from most of the eastern United States (36). In the absence of pumas and sometimes other large carnivores, hyperabundant cervids [such as the white-tailed deer (Odocoileus virginianus)] in the eastern United States and Canada now affect many aspects of ecosystem function, including plant recruitment and survival, endangered species status, forest stand structure, nutrient dynamics, and socioeconomics through vehicle collisions (37). Where pumas are present, they can be important drivers of cervid populations and associated trophic relations, as in canyon settings in western North America, where they locally limit mule deer $(O$. hemionus) densities, releasing woody plants from browsing suppression $(38,39)$. Pumas also appear to influence processes affecting terrestrial and aquatic species, including hydrophytic plants, wildflowers, amphibians, 
lizards, and butterflies. Their presence may also help to stabilize stream banks and channels (38). Pumas may induce their prey to engage in "human shielding" as an antipredator strategy. Deer at risk from pumas, for example, associated themselves with human development at high densities, in turn causing plant damage $(38,39)$.

\section{Other Large Carnivores}

Little is known about the ecological effects of the other large-carnivore species listed in Table 1, and questions remain about their potential roles in controlling food webs and ecosystem functioning, especially in the tropics and subtropics (Fig. 5). However, some valuable lessons come from the flooding of a forest region in Venezuela to generate hydroelectric power. This once-intact, productive tropical system was composed of a species-rich food web with multiple linkages among species. Flooding fragmented the region to produce mountaintop islands - the Lago Guri islands — resulting in the loss of an entire predator guild of jaguars (Panthera onca), pumas, lesser mammalian predators, large raptors, and snakes (40). This loss of predators had cascading effects on species of pollinators, seed dispersers, seed predators, folivores, and mesopredators, as well as on woody plant recruitment, bird abundance, and soil carbon/nitrogen ratios (41).

Predator species often co-occur, requiring consideration of their joint effects. Multiple predator effects on prey species and on ecosystems can be synergistic (15). Thus, in some cases, the strength of a trophic cascade may be due to synergisms owing to complementarity among species in the top carnivore guild of communities. This implies that the combined effects of predator species may need to be conserved to fully ensure control over communities and ecosystem functioning. For example, bears of northern latitudes (Ursus spp.) may control the recruitment of juveniles into populations of their prey species (42). Because bears are opportunistic omnivores and eat a variety of foods, their effects may complement those of gray wolves (34). In North America, both black (U. americanus) and brown (U. arctos) bears commonly prey on neonatal cervids, taking a large percentage of the annual offspring that are less than 1 month old, and these effects could be additive. In Yellowstone National Park, bears killed more elk (Cervus elaphus) calves than did gray wolves, coyotes (Canis latrans), and pumas combined (43). In Europe, roe deer densities were significantly lower in areas with sympatric wolves and lynx than in areas with wolves alone or areas where both predators were absent $(24,34)$. The effect of multiple predators on prey, however, need not always be synergistic. Adult female elk mortality was similar in areas of western North America with pumas alone as compared to areas with sympatric pumas and wolves (44).

Questions persist about how large-carnivore effects interact with habitat productivity. Theory

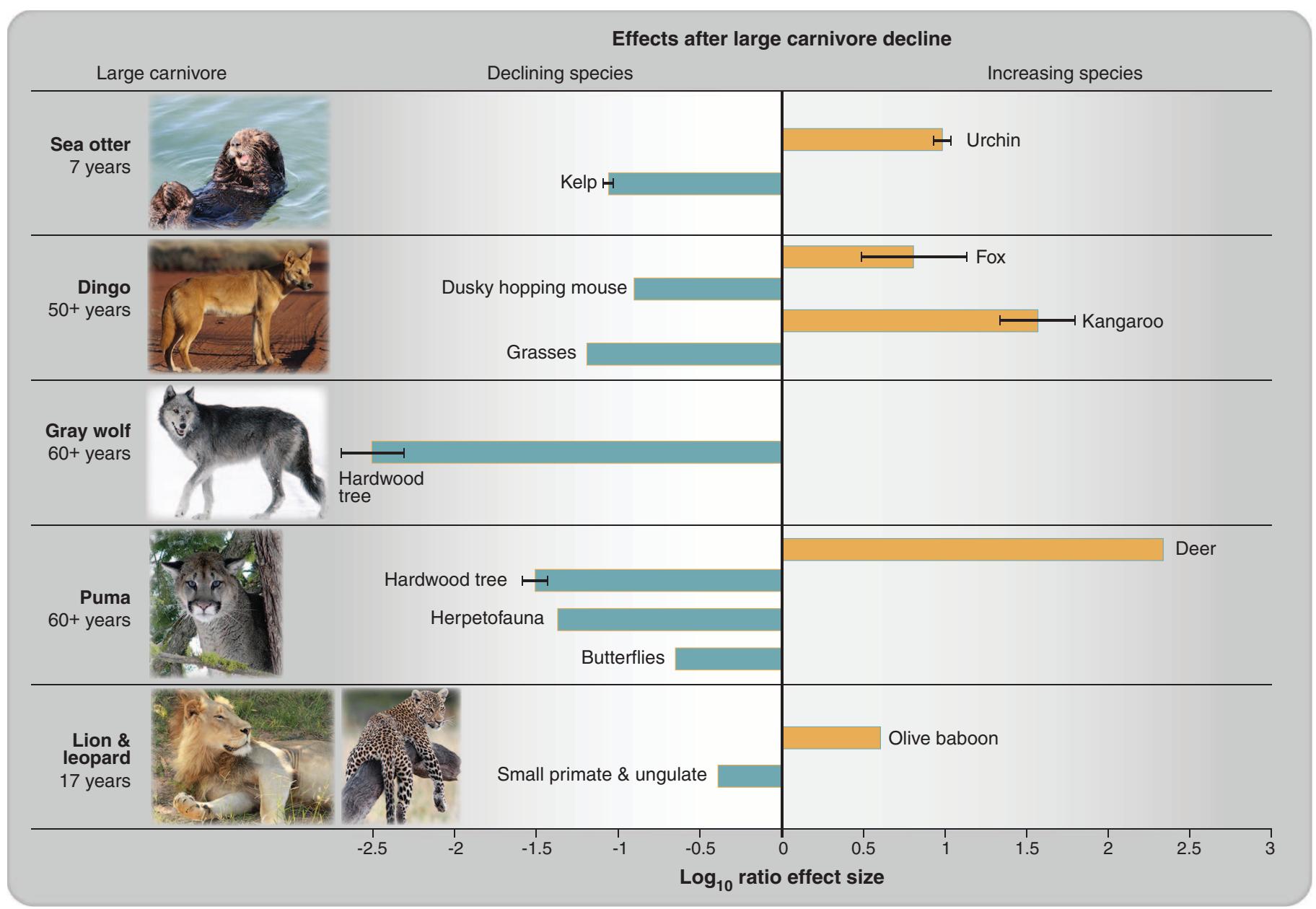

Fig. 2. Examples of effect sizes, shown as $\log _{10}$ ratios, after the removal of large-carnivore species. Sea otters $(29,92)$, dingoes-foxes and dingoes-kangaroo $(21,93)$, dingoes-mice (Notonmys fuscus) (93), dingoesgrasses (20), gray wolves-hardwood trees $(94,95)$, pumas-hardwood trees $(38,39)$, pumas-deer-herpetofauna-butterflies $(38)$, and lions and leopards (18). The number of years refers to the time since large-carnivore extirpation. The $\log _{10}$ ratios were calculated by dividing the values of each response variable without predator by those with predator and then taking the $\log _{10}$ of that ratio. Positive log ratios 10 indicate a positive effect, and negative $\log _{10}$ ratios indicate a negative effect of removing large carnivores. For studies using time-series data, we used the final sampling date in our analysis. The orange bars indicate direct effects and the blue bars indicate indirect effects. Error bars represent standard errors and were only available in some cases. [Photo credits: sea otter (N. Smith), dingo (A. McNab), gray wolf (Yellowstone National Park), puma (Washington Department of Fish and Wildlife), lion (K. Abley), leopard (A. Dey)] 
predicts that the strength of cascading effects may vary with the productivity of ecosystems and should show a "humped relationship" with ecosystem productivity $(26,27)$. That is, we might not expect to see strong trophic cascades in ecosystems such as extreme deserts, high elevations, or high latitudes, where low primary productivity limits herbivore populations and where there is insufficient energy available to support populations of large carnivores (27). The trophic effects of single carnivore species might also be diminished in extremely productive environments, because prey species diversity may also be high in such systems and, consequently, the strength of interspecific interactions is diffused across a greater number of interaction pathways $(20,41,45)$. For example, in a productive tropical forest, Sunda clouded leopards (Neofelis diardi) had no measurable effect on the abundance of the main large ungulate prey species (46). Conversely, there is also empirical evidence indicating that some canids consistently limit prey densities regardless of ecosystem productivity $(34,47)$. Accordingly, more analyses of how productivity interacts with trophic interactions are needed. To this end, regions harboring large-carnivore populations with different conservation statuses, including places without them, can be used as broad bioclimatic contexts for natural experiments.

\section{Ecosystem and Economic Services}

Large carnivores deliver economic and ecosystem services in a variety of direct and indirect ways. Because of their iconic and charismatic nature, large carnivores provide direct economic benefits associated with tourism. In both Minnesota and Yellowstone $(48,49)$ and the African photosafari industry (50), the opportunity to simply observe large carnivores can drive tourism revenue. In Yellowstone alone, wolf-related tourism expenditures range from $\$ 22$ million to $\$ 48$ million (in U.S. dollars) per year (49).

Large carnivores also have strong potential to indirectly deliver ecosystem services, such as carbon storage to buffer climate change, biodiversity enhancement, reestablishment of native plant diversity, riparian restoration, and even regulation of diseases. In some ecosystems, large carnivores may enhance carbon storage by limiting the numbers of their herbivore prey, thus allowing plants (all of which absorb and store $\mathrm{CO}_{2}$ ) to flourish. Carnivore conservation and restoration might reverse declines in forests stands and production, thereby aiding carbon storage, especially in the highly productive tropics, where declines in plant biomass occur after predator extirpation $(40,41)$. Maintaining gray wolf populations and their interactions with moose is estimated to help store significant amounts of carbon in boreal ecosystems (51). The restoration of sea otter populations can reduce sea urchin herbivores, thereby allowing kelp ecosystems to flourish at levels that can, in the North American range, lead to a 4.4- to 8.7-teragram increase in stored carbon valued at \$205 million to \$408 million (in U.S. dollars) on the European Carbon Exchange (52). Predators may enhance scavenger diversity (53) and thereby contribute to nutrient cycling, in addition to myriad other documented cascading and ramifying pathways (15). In riparian systems, large carnivores may reduce stream bank erosion through the growth of woody plants and enhance water quality and flood control through the restoration of beaver that benefit from the restored plants (54-57). Large carnivores help reduce disease prevalence in ungulate prey populations, thereby mitigating agricultural costs because of spillover effects on domestic livestock (58). Perhaps counterintuitively, large carnivores may also provide crucial services for the very industry they are perceived to be at most in conflict with: pastoralism. By limiting the density of wild herbivores and promoting productivity, large carnivores may enable pastoral activities that are sustainable $(12,59)$. This is not to deny that large carnivores also have direct costs, often associated with livestock losses (60), and balancing these costs against potential benefits for human-dominated ecosystems as a whole is a pressing challenge (61). Regardless, the potentially widespread beneficial ecosystem and economic services associated with large carnivores are underappreciated by society.

\section{Anthropogenic Impacts}

Large-carnivore population declines are typically precipitated by multiple, and sometimes concurrent, human threats, including habitat loss and degradation, persecution, utilization (such as for traditional medicine, trophy hunting, or furs), and depletion of prey. Globally, the strength of these threats varies substantially by region (Fig. 6 and table S2). These threats are sometimes localized to only parts of a carnivore's range and, in some cases, may extend beyond its range, thus acting to limit reoccupation of former habitats.

\begin{abstract}
Fig. 3. Examples of plant response after sea otter reduction and after gray wolf recovery. (A) An area of seafloor near Kirilof Point, Amchitka Island, Alaska, in 1971 (upper left, photo by P. Dayton), at which time sea otters were abundant, and in 2001 (lower left, photo by $M$. Kenner) at which time sea otter numbers had been reduced by more than $90 \%$ by killer whale predation. (B) Photos of the Yellowstone Northern Range taken in October 1994 (top right, photo by National Park Service) and November 2012 (bottom right, photo by D. Mclaughlin), showing increased recruitment of aspen since wolf reintroduction in 1995-1996 at the site of the Crystal Creek gray wolf holding pen, which was removed in 1998. Young aspen in the 1994 photo were mostly less than $1 \mathrm{~m}$ tall and those in the 2012 photo were typically 3 to $4 \mathrm{~m}$ tall.
\end{abstract}
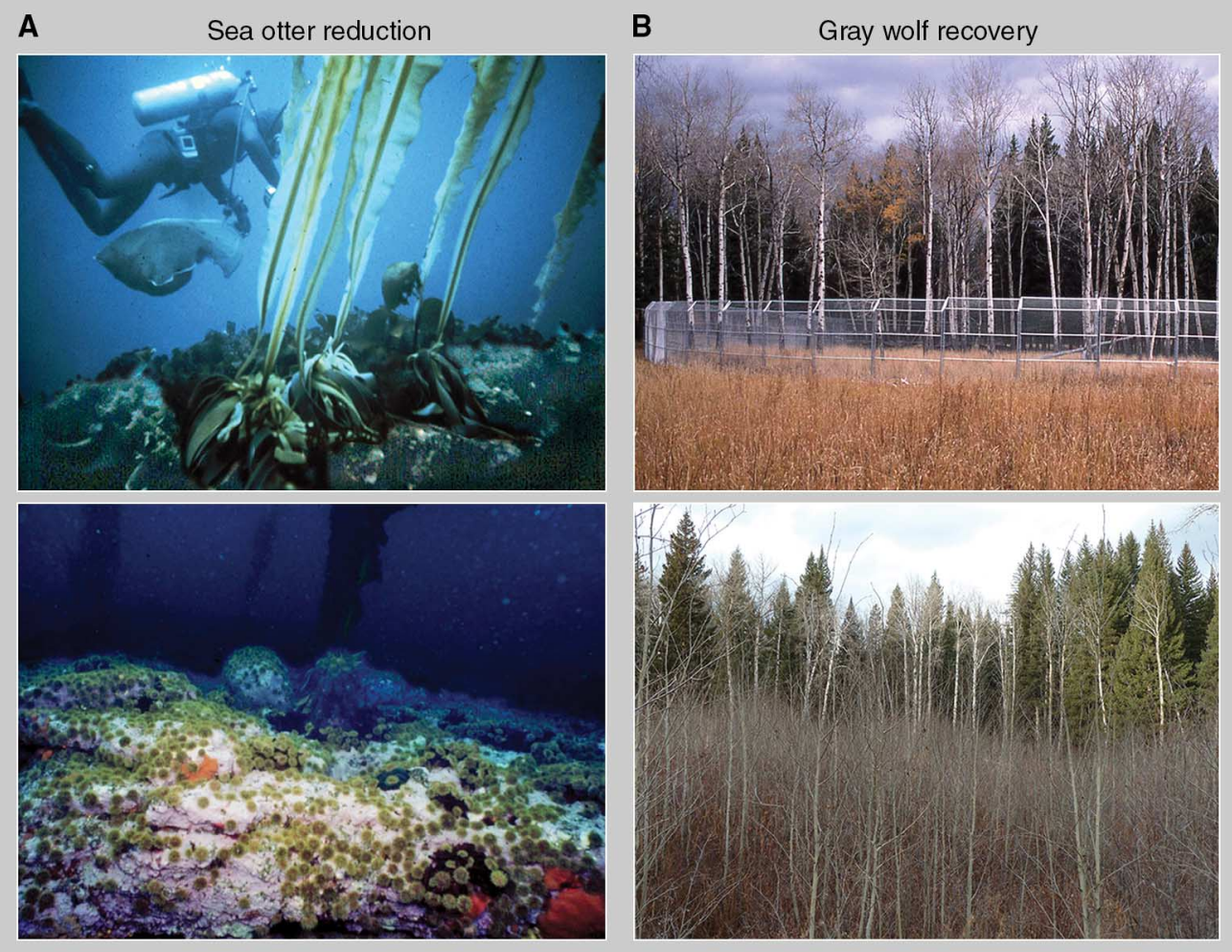
Human actions may dampen or even eliminate cascading effects. For example, Mexican gray wolves in southwestern North America have not yet been restored to an ecologically effective density in relation to that of their main prey, elk, because of ongoing conflicts with livestock grazing and repeated management translocations (62). Likewise, recent wide-scale hunting of recovering gray wolf populations in parts of the Great Lakes region and the western United States may reduce wolf populations below sizes at which they are able to exert their effects on communities and ecosystems (63-65). Furthermore, wolves and other carnivores may have little influence on other species in areas where human hunters have disproportionate effects on prey densities (66). Few large carnivores can persist in parts of Latin America, Asia, and Africa because of the loss of wild ungulate prey species caused by activities such as hunting for bushmeat. The extraction of bushmeat, in turn, has created "empty forests" (1). Conversely, hyperabundant exotic ungulates (domestic livestock) are present in much of the world. These livestock are a potential prey base and thus a continuing source of conflict between humans and large carnivores (17).

Hunting by humans, whether legal as in North America and Europe or illegal as in the pantropical bushmeat trade, may itself cause trophic cascades, because humans are also predators with the potential for ecological impacts. Indeed, human hunting pressure on moose (Alces alces) has led to the release of control on willow (Salix spp.) shrub production and hence encouraged increases in neotropical migrant bird abundances (42). Although it is often claimed that human hunting substitutes for predators, it remains doubtful whether such substitution actually leads to the same functional consequences for communities and ecosystems. Effects may be different because of differences in the intensity and timing of predation by humans versus predators, as well as hunting effects on the behavior, age, and sex of prey (67). Many carnivores hunt year-round, day or night, and away from human access points. The behavioral responses of prey to predation risk caused by carnivores may create an "ecology of fear" with myriad cascading effects on ecosystems (68). In the end, it is not surprising that various human activities in Australia (12), North America (13,34), and Eurasia (24) have been unsuccessful in substituting for large carnivores to control populations of native and nonnative herbivores and mesopredators. The huge importance of carnivores is exemplified by the fact that humans typically cannot replicate the effects of carnivores on ecosystems.

Habitat fragmentation, and more generally the intensity of human uses of landscapes, continue to be persistent threats to larger-bodied carnivores, with the potential for cascading impacts on species diversity $(5,38)$. There exists, therefore, an increasing need to understand the interacting effects of anthropogenic land-use changes and altered large-carnivore guilds on community structure and function. Because of differences in their ecology and human tolerance, pumas are able to persist in areas with much higher levels of human land use than are gray wolves, even though these two carnivores are of similar size. Such differential predator species loss in the face of landscape changes may be especially critical if synergism among multiple large carnivores within predator guilds is required to maintain control over prey populations $(34,43)$. These and other carnivore species make kills in different habitats, or scavenge to supplement their diets, which can determine the nature and rates of prey kills and consumption $(53,69)$. In addition to altering predator communities, increased human land use can alter nutrient and water availability, thereby mitigating natural controls over ecological communities and ecosystem functioning (70).

Perhaps one of the most insidious threats to carnivores is global human population size and its associated resource consumption, which are expected to continue rising significantly through at least 2050 (Fig. 7). Increased human population size can lead to increased demand for meat. Interestingly, human carnivory competes with

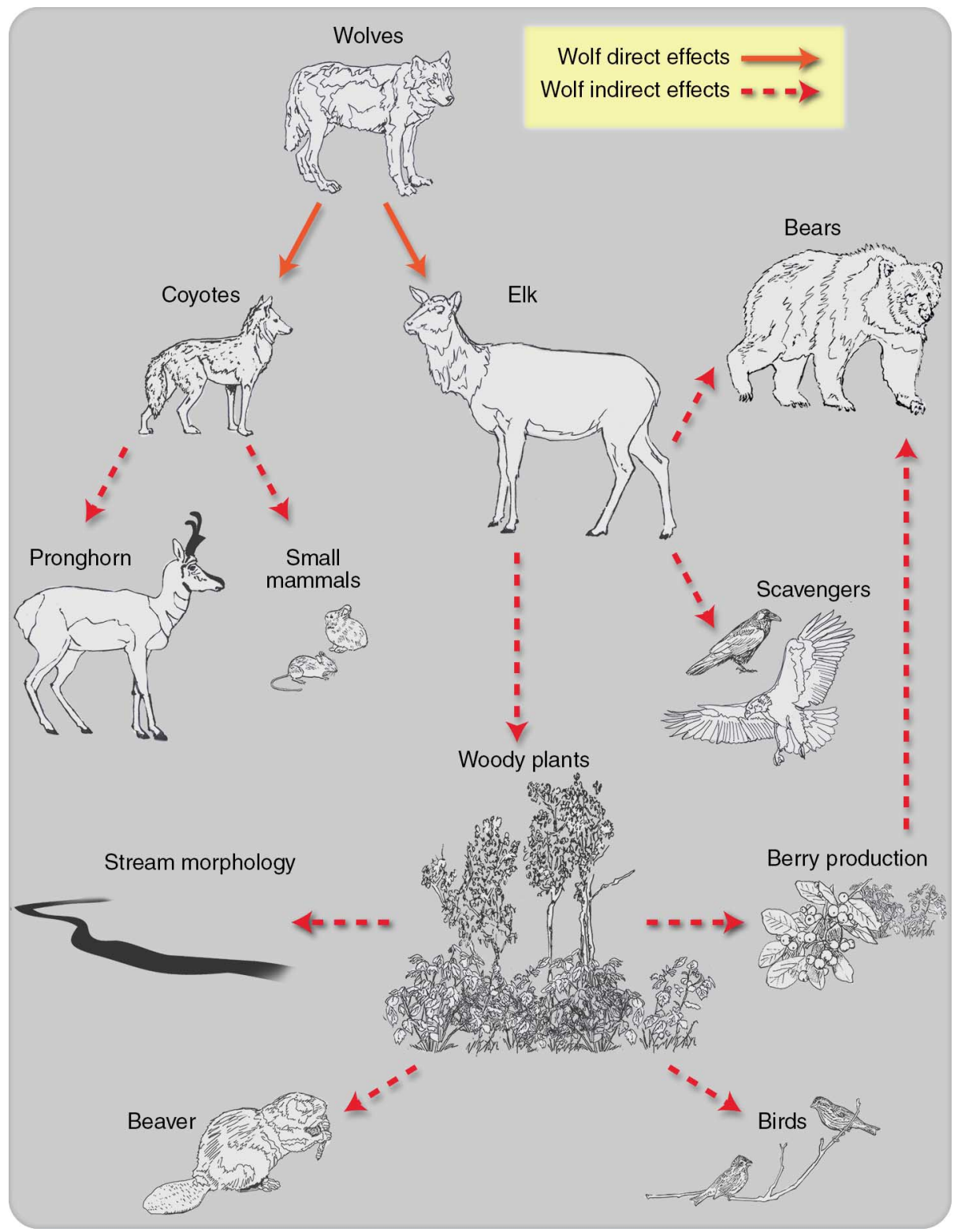

Fig. 4. Conceptual diagram showing direct (solid lines) and indirect (dashed lines) effects of gray wolf reintroduction into the Greater Yellowstone ecosystem. Wolf direct effects have been documented for elk (96) and coyotes (97), whereas indirect effects have been shown for pronghorn (98), small mammals (99), woody plants (100), stream morphology (54), beaver (55), birds (101), berry production $(63)$, scavengers $(53)$, and bears $(56,63)$. This is a simplified diagram, and not all species and trophic interactions are shown. For example, the diagram does not address any potential top-down effects of pumas, bears, and golden eagles (Aquila chrysaetos), which are all part of the Yellowstone predator guild where juvenile or adult elk are prey. 
large carnivores. For example, the need for humans to either produce meat through livestock production or to exploit wild sources necessarily puts extra pressure on large carnivores on multiple fronts, including ongoing habitat loss from land conversion, depletion of prey, and direct persecution due to conflicts with livestock. In light of their slow life histories and requirement for large continuous habitat, such trends exacerbate the vulnerability of large carnivores to extinction (9). Increases in both human population and meat consumption can also affect biodiversity, greenhouse gas emissions, food security, deforestation, desertification, and water quality and quantity $(71,72)$. Therefore, policy for carnivore conservation needs to be joined up with policy addressing these other converging issues having implications at the global scale $(71,72)$. Ideally, discussions regarding potential decreases in both human fertility rates and per-capita meat consumption would be part of a long-term strategy for overcoming these concurrent challenges.

\section{Climate Change}

Looking forward, the status of large carnivores will influence the extent to which individual species, biotic communities, and ecosystems respond to climate change. For example, mesopredators that have been released from control by the loss of their carnivore predators may increase further in abundance wherever climate change relaxes limitations on their own prey (23). Large carnivores may instrumentally determine resilience against invading species, because both native and introduced species are less likely to become invasive in ecosystems in which food-web interdependencies remain intact (7). These potential buffering capacities remain both poorly appreciated and poorly understood. Widespread modeling approaches forecasting climate change effects on species still simplistically assume that such interactions and interdependencies do not require consideration, let alone quantification (73). Furthermore, climate change is already causing species geographic range shifts that stand to disrupt existing species interactions $(74,75)$. As species move at different rates and in different directions, novel communities are likely to be created as new combinations of predator and prey species assemble on landscapes. The recently documented change in hunting locations and food habits among polar bears (Ursus maritimus) is a case in point. With receding sea ice, polar bears have more difficulty hunting seals, their traditional prey, and are now feeding onshore on the eggs of migratory waterfowl (76).
As climate change progresses, large carnivores might serve as important buffers or amplifiers of effects on ecosystems (77). In Yellowstone National Park, reintroduced gray wolves control the timing and abundance of ungulate carrion resources, on which a suite of scavenger species, ranging in size from grizzly bears to magpies (Pica hudsonia), depend for winter survival and reproduction. The return of wolves has buffered the influence of climate change on late-winter carrion availability (77) by shifting the dynamics of carrion availability from a boom-and-bust cycle, linked to climate variability, to a more dependable resource based on shifting patterns of wolf pack size (53). Large carnivores might also help augment ecosystem carbon storage by suppressing herbivores, thereby allowing plants to flourish (34). For instance, the decline of large carnivores in western North America was followed by a decline in hardwood tree recruitment in riparian areas of over two orders of magnitude (6). In northern North America, gray wolves limiting moose populations may be responsible for increased net ecosystem uptake of carbon due to decreased browsing and increased net primary productivity (51). Likewise, the presence of sea otters in nearshore environments suppresses sea urchins, allowing macroalgael kelp to thrive and thereby

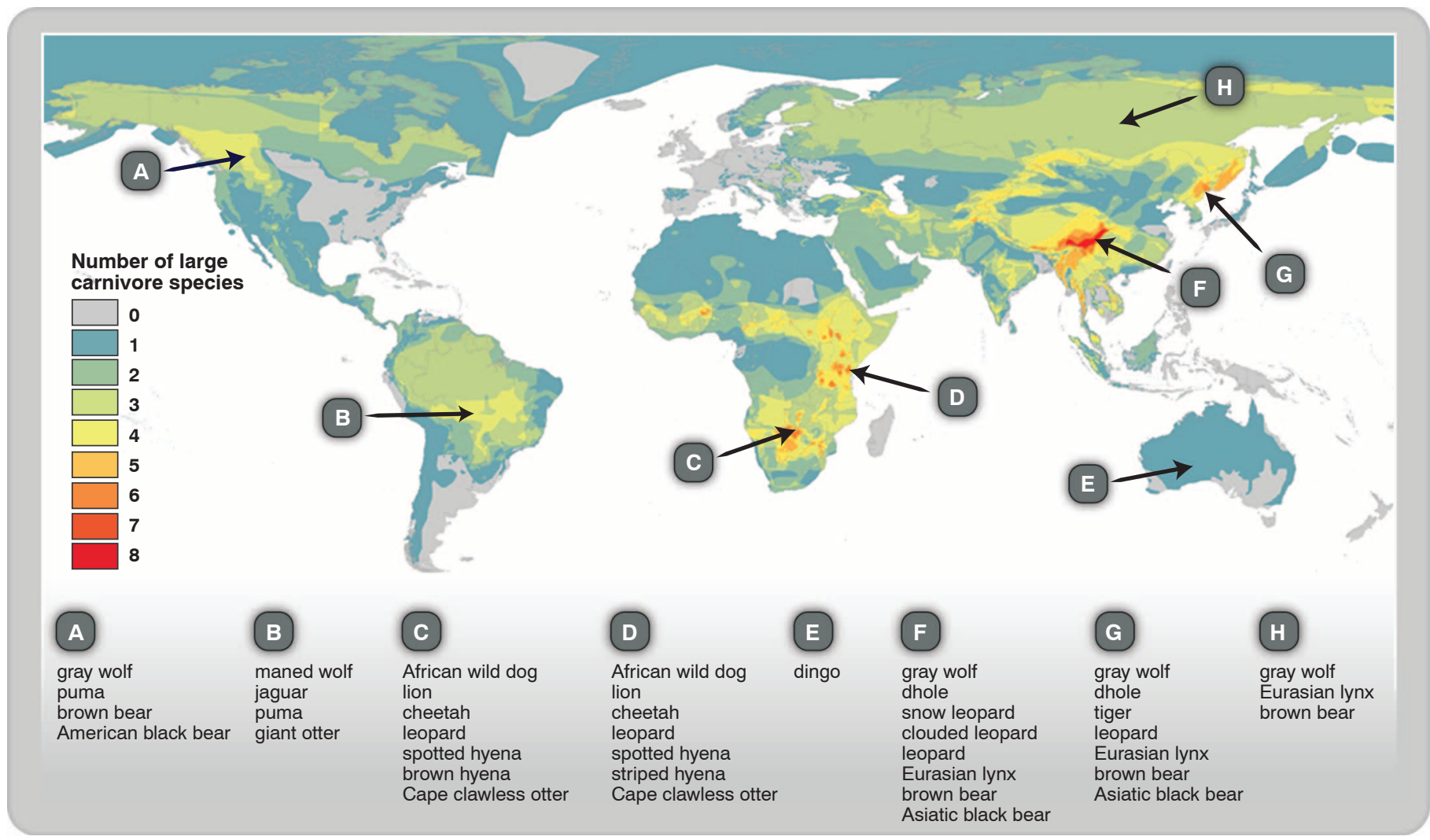

Fig. 5. Contemporary overlap of large carnivore ranges throughout the world. Compared to historical times, large-carnivore range contractions have been most extensive in Europe, southeastern North America, and western and central Africa. The areas with the highest number of species and with intact largecarnivore guilds are some of the best regions for research and conservation (e.g., southeastern Asia, eastern and southern Africa, and northwestern North America).
Northern Eurasia is the region with the most expansive range for a three-species guild (gray wolves, Eurasian lynx, and brown bear). The percent of the total terrestrial land area in each of the eight classes in the map includes $0,13.3 \% ; 1$, $29.1 \%$; 2, 23.5\%; 3, 20.5\%; 4, 9.1\%; 5, 2.8\%; 6, 1.1\%; 7, 0.4\%; 8, 0.1\%. Only $\sim 5 \%$ of Earth's land surface currently contains more than four overlapping largecarnivore species. See fig. S4 for individual range maps. Source: IUCN (91). 
increasing ecosystem carbon production and storage by one to two orders of magnitude (52). Globally, several billion head of ruminating livestock affect global climate change by contributing significant amounts of methane, nitrous oxide, and carbon dioxide ( $\sim 5.7$ gigatons of $\mathrm{CO}_{2}$ equivalent per year) to the atmosphere, making domestic ruminants a significant contributor to climate change (11.6\% of all anthropogenic emissions of greenhouse gases) (72). Decreasing global livestock numbers to reduce greenhouse gas emissions would both mitigate climate change and benefit large-carnivore conservation by reducing ongoing worldwide conflict between large carnivores and livestock.

\section{Outlook}

The loss of large carnivores across global ecosystems is predicted to lead to two general outcomes. First, as apex predators are lost, we should expect continued change in cascading controls over communities and ecosystem function. Although these effects will differ with the variation in precipitation, temperature, productivity, diversity, and overall landscape features, the continued loss of carnivores nonetheless will be accom- panied by changes in plant species diversity, biomass, and productivity. In forest and arid ecosystems, the loss of palatable perennial plant species may interact with global warming to increase the rate of desertification. Because plants are the trophic foundation of all ecosystems, these vegetation changes can be expected to have wide-ranging influences on virtually all other species. The growing list of case studies, some of which we presented above, may well represent the tip of the proverbial iceberg. Changes in species abundance resulting from the loss of large carnivores can be expected to influence numerous other ecological processes, including disease dynamics $(78,79)$, wildfire $(80)$, and carbon sequestration (51). Furthermore, the effects of large carnivores are now known to have wide ramifications through highly interconnected food-web networks within their associated ecosystems (81). Second, we should expect surprises, because we have only just begun to understand the influences of these animals in the fabric of nature (82).

The classic conception of large-carnivore influences on ecosystems held that predators were responsible for depleting resources such as fish, wildlife, and domestic livestock. This assumption is still used to justify wildlife management practices aiming to limit or eradicate predators in some regions $(83,84)$. This conception of carnivore ecology is now outdated and in need of fundamental change. Indeed, evidence shows that their roles are far more complex and varied, and their myriad social and economic effects on humans include many benefits. Conservation decisions must begin to account for these integral roles and the attendant economic costs of carnivore species losses.

Currently, the IUCN Species Survival Commission (SSC) action plan series represents perhaps the most comprehensive attempt to establish priorities for individual species or taxa $(84,85)$. These action plans not only provide assessments of threats but recommend conservation monitoring and actions for each large-carnivore species (table S3). Action plans are compiled by the taxonomically organized SSC's Specialist Groups (for example, the Canid Specialist Group compiles action plans for all canid species). Large carnivores, however, also share common conservation challenges that cross taxonomic boundaries: slow life histories, requirement for extensive and continuous habitat, low densities, complex

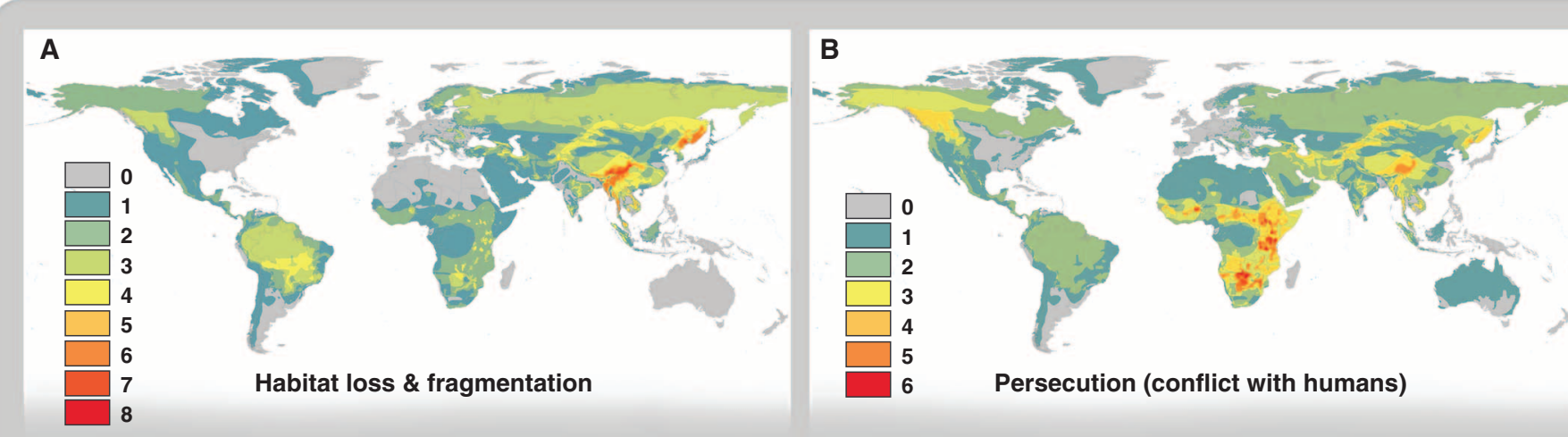

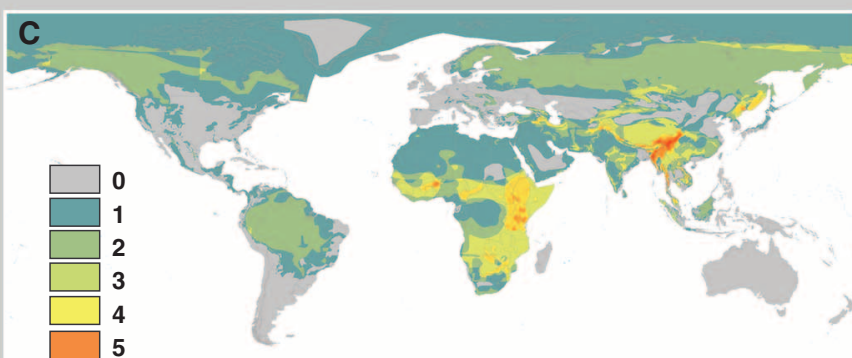

Utilization (e.g. traditional medicine, fur)

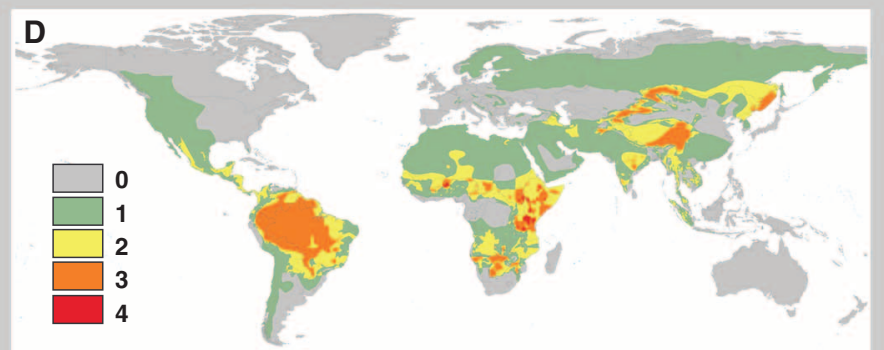

Depletion of prey
Fig. 6. Maps showing the the spatial overlap for the ranges of largecarnivore species by threat category for habitat loss and fragmentation, persecution, utilization, and depletion of prey. The number of large-carnivore species affected by specific threats is shown in the map legend. Threat catgories include: (A) Habitat loss and fragmentation. Forest logging and/or the development of urban, agricultural, and road infrastructure reduces land available to large carnivores and creates barriers between and within populations. (B) Persecution. Culling (poison baiting, trapping, and shooting) for the purpose of removal or reduction, in some cases reinforced with a government-subsidized bounty system, in response to real or perceived threat to pastoral and agricultural activities and human lives. (C) Utilization. Large carnivores are killed for sport, body parts for traditional medicine, fur, and meat for human consumption, and live animals are captured and sold. (D) Depletion of prey. The decline of prey populations due to human hunting, competition with livestock, habitat loss, and other factors reduces the prey base for large carnivores. See table S2 for raw data. Source: IUCN (91). 
social structures, importance to ecological function, and conflict with humans. These common traits and challenges have given rise to the creation of the Large Carnivore Initiative for Europe, a Specialist Group whose vision is "to maintain and restore, in coexistence with people, viable populations of large carnivores as an integral part of ecosystems and landscapes across Europe" (86). We propose the expansion of this initiative, to establish a Global Large Carnivore Initiative (GLCI).

There is now a substantial body of research demonstrating that, alongside climate change, eliminating large carnivores is one of the most significant anthropogenic impacts on nature (5). Unlike climate change, however, large-carnivore conservation has yet to become a focus of widespread public recognition, possibly because they are rare, remote, and in some cases perceived to be dangerous and a threat to economic prosperity. The formation of a GLCI would be an important step for the advancement of international public recognition of the ecological role and inherent value of large carnivores, and for developing and coordinating strategies for conservation actions that promote human/large-carnivore coexistence. Such an organization could be modeled, in part, after the Global Tiger Initiative, which is coordinating local, national, and international tiger conservation policy across their distribution and was endorsed in 2010 by the leaders of all 13 tiger-range countries, with funding from the World Bank (87). These 13 countries and partners have moved well beyond words to accomplishments on the ground, including securing funding, establishing new tiger reserves, passing laws on tiger conservation, creating high-level commissions to improve wildlife law enforcement, addressing habitat loss and fragmentation, promoting connectivity, and more (87). The success of any future GLCI would probably include these types of authoritative actions, orchestrated by politi- cally bold commitments from nations around the world.

\section{A Final Word}

One of the main ecological arguments for the conservation of large carnivores is that they are often capable of exerting strong regulatory effects on ecosystems $(5,15)$. Although we present evidence that seven of the top carnivore species we reviewed here have such trophic effects, we know much less about the trophic impacts of the 24 other species of large carnivores. More research directed at these species is needed. Also, we need a better understanding of minimum required densities for large carnivores to maintain trophic cascades in different ecosystems, and when and where the strength of those effects is likely to be large versus small. It is also important to understand which human activities are most in conflict with the conservation of specific large carnivores.

A crucial societal challenge is finding creative solutions to maintain viable populations of large carnivores in the face of alternative land uses $(7,59)$. This is most urgent because global livestock production continues to encroach on land needed by large carnivores, particularly in the developing world, where livestock production tripled between 1980 and 2002 (88). If the world continues to transition into one that replaces top carnivores with livestock and mesopredators, it is incumbent on us to understand more about the ecological effects of such a downward ratcheting on ecosystems. More large and livestock-free protected areas are needed, especially in regions such as southeastern Asia, where large-carnivore richness (Fig. 5) remains the highest in the world. Yet even in these regions, carnivore populations are decreasing (Table 1) and few large reserves exist (fig. S3). More protected areas alone will not be sufficient, so strategies are also needed to facilitate human coexistence with these animals across working landscapes (59).

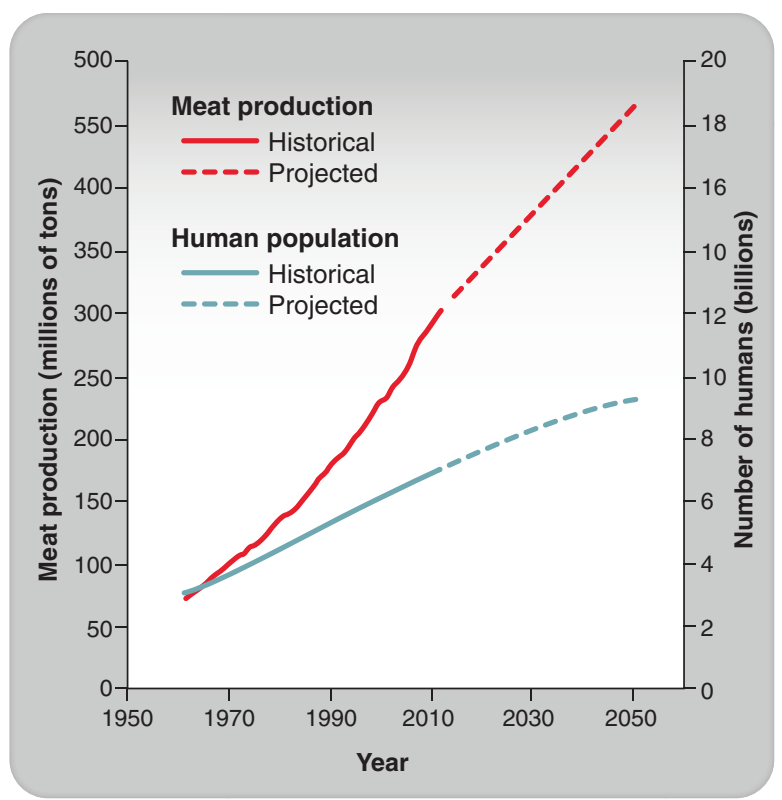

Large-carnivore conservation might best be served by a two-pronged approach. First, there is a need for increased recognition of and focus on conserving the full range of the potential effects provided by large carnivores, because this may lead to broader biodiversity, as well as social and economic benefits $(5,15,89)$. In areas where large carnivores have been displaced or locally extirpated, their reintroduction may represent a particularly effective approach for passively restoring those ecosystems. However, harnessing the positive effects of large carnivores while (i) minimizing their impacts on humans and (ii) getting humans to adapt to large-carnivore presence, represents a major sociopolitical challenge. Biodiversity conservation programs intended to retain or reintroduce large carnivores must ultimately address both of these challenges if they are to succeed. Second, large-carnivore conservation might also be seen as a moral obligation - the recognition of the intrinsic value of all species. A 40-year history of the field of environmental ethics has both rigorous and systematic rationales for valuing species and nature itself. Largecarnivore conservation, therefore, might benefit greatly from a more formal relationship with practitioners of environmental ethics. It will probably take a change in both human attitudes and actions to avoid imminent large-carnivore extinctions. A future for these carnivore species and their continued effects on planet Earth's ecosystems may depend upon it.

\section{References and Notes}

1. L. Hunter, Carnivores of the World (Princeton Univ. Press, Princeton, N], 2011).

2. G. Ceballos, P. R. Ehrlich, Mammal population losses and the extinction crisis. Science 296, 904-907 (2002). doi: 10.1126/science.1069349; pmid: 11988573

3. J. C. Morrison, W. Sechrest, E. Dinerstein, D. S. Wilcove, J. F. Lamoreux, Persistence of large mammal faunas as indicators of global human impacts. J. Mammal. 88, 1363-1380 (2007). doi: 10.1644/06-MAMM-A-124R2.1

4. L. R. Prugh et al., The rise of the mesopredator Bioscience 59, 779-791 (2009). doi: 10.1525/ bio.2009.59.9.9

5. J. A. Estes et al., Trophic downgrading of planet Earth. Science 333, 301-306 (2011). doi: 10.1126/ science.1205106; pmid: 21764740

6. R. L. Beschta, R. J. Ripple, Large predators and trophic cascades in terrestrial ecosystems of the western United States. Biol. Conserv. 142, 2401-2414 (2009). doi: 10.1016/j.biocon.2009.06.015

7. E. G. Ritchie et al., Ecosystem restoration with teeth: What role for predators? Trends Ecol. Evol. 27, 265-271 (2012). doi: 10.1016/j.tree.2012.01.001; pmid: 22321653

8. C. Carbone, G. M. Mace, S. C. Roberts, D. W. Macdonald, Energetic constraints on the diet of terrestrial carnivores. Nature 402, 286-288 (1999). doi: 10.1038/46266; pmid: 10580498

9. M. Cardillo et al., Human population density and extinction risk in the world's carnivores. PLOS Biol. 2, e197 (2004). doi: 10.1371/journal.pbio.0020197; pmid: 15252445

10. M. Cardillo et al., Multiple causes of high extinction risk in large mammal species. Science 309, 1239-1241 (2005). doi: 10.1126/science.1116030; pmid: 16037416

11. C. Carbone, J. L. Gittleman, A common rule for the scaling of carnivore density. Science 295, 2273-2276 (2002). doi: 10.1126/science.1067994; pmid: 11910114

12. A. D. Wallach, C. N. Johnson, E. G. Ritchie, A. J. O'Neill, Predator control promotes invasive dominated ecological 
states. Ecol. Lett. 13, 1008-1018 (2010). pmid: 20545732

13. W. J. Ripple, A. J. Wirsing, C. C. Wilmers, M. Letnic, Widespread mesopredator effects after wolf extirpation. Biol. Conserv. 160, 70-79 (2013). doi: 10.1016/ j.biocon.2012.12.033

14. E. G. Ritchie, C. N. Johnson, Predator interactions, mesopredator release and biodiversity conservation. Ecol. Lett. 12, 982-998 (2009). doi: 10.1111 j.1461-0248.2009.01347.x; pmid: 19614756

15. O. J. Schmitz, D. Hawlena, G. C. Trussell, Predator control of ecosystem nutrient dynamics. Ecol. Lett. 13, 1199-1209 (2010). doi: 10.1111/j.1461-0248.2010. 01511.x; pmid: 20602626

16. E. T. Borer et al., What determines the strength of a trophic cascade? Ecology 86, 528-537 (2005). doi: 10.1890/03-0816

17. J. C. Ray, L. Hunter, ]. Zigouris, Setting Conservation and Research Priorities for Larger African Carnivores (Report No. 24, Wildlife Conservation Society, New York, 2005).

18. J. S. Brashares, P. R. Prugh, C. J. Stoner, C. W. Epps, in Trophic Cascades: Predators, Prey, and the Changing Dynamics of Nature, ]. Terborgh, J. A. Estes, Eds. (Island Press, Washington, DC, 2010), pp. 221-240.

19. P. Savolainen, T. Leitner, A. N. Wilton, E. Matisoo-Smith J. Lundeberg, A detailed picture of the origin of the Australian dingo, obtained from the study of mitochondrial DNA. Proc. Natl. Acad. Sci. U.S.A. 101, 12387-12390 (2004). doi: 10.1073/pnas.0401814101; pmid: 15299143

20. M. Letnic, E. G. Ritchie, C. R. Dickman, Top predators as biodiversity regulators: The dingo Canis lupus dingo as a case study. Biol. Rev. Camb. Philos. Soc. 87, 390-413 (2012). doi: 10.1111/j.1469-185X.2011.00203.x pmid: 22051057

21. M. Letnic, M. S. Crowther, F. Koch, Does a top-predator provide an endangered rodent with refuge from an invasive mesopredator? Anim. Conserv. 12, 302-312 (2009). doi: 10.1111/j.1469-1795.2009.00250.x

22. C. N. Johnson, J. L. Isaac, D. O. Fisher, Rarity of a top predator triggers continent-wide collapse of mammal prey: Dingoes and marsupials in Australia. Proc. Biol. Sci. 274, 341-346 (2007). doi: 10.1098/rspb.2006.3711; pmid: 17164197

23. M. Pasanen-Mortensen, M. Pyykönen, B. Elmhagen, Where lynx prevail, foxes will fail - regulation and limitation of a mesopredator in Eurasia. Glob. Ecol. Biogeogr. 22, 868-877 (2013). doi: 10.1111/geb.12051

24. C. Melis et al., Predation has a greater impact in less productive environments: Variation in roe deer, Capreolus capreolus, population density across Europe. Glob. Ecol. Biogeogr. 18, 724-734 (2009). doi: 10.1111/j.1466-8238.2009.00480.x

25. B. Elmhagen, G. Ludwig, S. P. Rushton, P. Helle, H. Lindén, Top predators, mesopredators and their prey: Interference ecosystems along bioclimatic productivity gradients. J. Anim. Ecol. 79, 785-794 (2010). pmid: 20337755

26. 0. J. Schmitz, Exploitation in model food chains with mechanistic consumer-resource dynamics. Theor. Popul. Biol. 41, 161-183 (1992). doi: 10.1016/0040-5809(92)90042-R

27. L. Oksanen, T. Oksanen, The logic and realism of the hypothesis of exploitation ecosystems. Am. Nat. 155 703-723 (2000). doi: 10.1086/303354; pmid: 10805639

28. K. W. Kenyon, The sea otter in the eastern Pacific Ocean North Am. Fauna 68, 1-352 (1969). doi: 10.3996 nafa.68.0001

29. J. A. Estes, M. T. Tinker, T. M. Williams, D. F. Doak, Killer whale predation on sea otters linking oceanic and nearshore ecosystems. Science 282, 473-476 (1998) doi: 10.1126/science.282.5388.473; pmid: 9774274

30. J. A. Estes, J. F. Palmisano, Sea otters: Their role in structuring nearshore communities. Science $\mathbf{1 8 5}$ 1058-1060 (1974). doi: 10.1126/science.185.4156.1058; pmid: 17738247

31. ]. A. Estes, C. H. Peterson, R. Steneck, in Trophic Cascades: Predators, Prey, and the Changing Dynamics of Nature, ]. Terborgh, J. A. Estes, Eds. (Island Press, Washington, DC, 2010), pp. 37-54.
32. B. Konar, ]. A. Estes, The stability of boundary regions between kelp beds and deforested areas. Ecology 84, 174-185 (2003). doi: 10.1890/0012-9658(2003)084 [0174:TSOBRB]2.0.CO;2

33. R. O. Peterson, J. A. Vucetich, R. E. Page, A. Chouinard, Temporal and spatial aspects of predator-prey dynamics. Alces 39, 215-232 (2003).

34. W. J. Ripple, R. L. Beschta, Large predators limit herbivore densities in northern forest ecosystems. Eur. J. Wildl. Res. 58, 733-742 (2012). doi: 10.1007/ s10344-012-0623-5

35. A. Leopold, L. K. Sowls, D. L. Spencer, A survey of over-populated deer ranges in the United States. J. Wildl. Manage. 11, 162-183 (1947). doi: 10.2307/3795561

36. A. S. Laliberte, W. J. Ripple, Range contractions of North American carnivores and ungulates. Bioscience 54 123-138 (2004). doi: 10.1641/0006-3568(2004)054 [0123:RCONAC]2.0.CO;2

37. S. D. Côté, T. P. Rooney, ]. P. Tremblay, C. Dussault, D. M. Waller, Ecological impacts of deer overabundance. Annu. Rev. Ecol. Evol. 35, 113-147 (2004).

38. W. J. Ripple, R. L. Beschta, Linking a cougar decline, trophic cascade, and catastrophic regime shift in Zion National Park. Biol. Conserv. 133, 397-408 (2006). doi: 10.1016/j.biocon.2006.07.002

39. W. J. Ripple, R. L. Beschta, Trophic cascades involving cougar, mule deer, and black oaks in Yosemite National Park. Biol. Conserv. 141, 1249-1256 (2008). doi: 10.1016/j.biocon.2008.02.028

40. ]. Terborgh et al., Ecological meltdown in predator-free forest fragments. Science 294, 1923-1926 (2001) doi: 10.1126/science.1064397; pmid: 11729317

41. ]. Terborgh, K. Freeley, in Trophic Cascades: Predators, Prey, and the Changing Dynamics of Nature, ]. Terborgh, J. A. Estes, Eds. (Island Press, Washington, DC, 2010), pp. $125-140$

42. J. Berger, P. B. Stacey, L. Bellis, M. P. Johnson, A mammalian predator-prey imbalance: Grizzly bear and wolf extinction affect avian neotropical migrants. Ecol. Appl. 11, 947-960 (2001)

43. S. M. Barber-Meyer, L. D. Mech, P. J. White, Elk calf survival and mortality following wolf restoration to Yellowstone National Park. Wildl. Monogr. 169, 1-30 (2008).

44. ]. Brodie et al., Relative influence of human harvest, carnivores, and weather on adult female elk survival across western North America. J. Appl. Ecol. 50, 295-305 (2013). doi: 10.1111/1365-2664.12044

45. G. A. Polis, D. R. Strong, Food web complexity and community dynamics. Am. Nat. 147, 813-846 (1996). doi: $10.1086 / 285880$

46. J. F. Brodie, A. Giordano, Lack of trophic release with large mammal predators and prey in Borneo. Biol. Conserv. 163, 58-67 (2013). doi: 10.1016/ j.biocon.2013.01.003

47. M. Letnic, M. S. Crowther, Patterns in the abundance of kangaroo populations in arid Australia are consistent with the exploitation ecosystems hypothesis. Oikos 122, 761-769 (2013). doi: 10.1111/j.1600-0706.2012.20425

48. C. M. Chambers, J. C. Whitehead, A contingent valuation estimate of the benefits of wolves in Minnesota. Environ. Resour. Econ. 26, 249-267 (2003). doi: 10.1023/A: 1026356020521

49. L. Richardson, ]. Loomis, The total economic value of threatened, endangered and rare species: An updated meta-analysis. Ecol. Econ. 68, 1535-1548 (2009). doi: 10.1016/j.ecolecon.2008.10.016

50. R. Naidoo et al., Effect of diversity of large wildlife species on financial benefits to local communities in northwest Namibia. Environ. Resour. Econ. 48, 321-335 (2011). doi: 10.1007/s10640-010-9412-3

51. 0. J. Schmitz et al., Animating the carbon cycle. Ecosystems 10.1007/s10021-013-9715-7 (2013). doi: 10.1007/s10021-013-9715-7

52. C. C. Wilmers, J. A. Estes, M. Edwards, K. L. Laidre, B. Konar, Do trophic cascades affect the storage and flux of atmospheric carbon? An analysis for sea otters and kelp forests. Front. Ecol. Environ 10, 409-415 (2012). doi: 10.1890/110176
53. C. C. Wilmers, R. L. Crabtree, D. W. Smith, K. M. Murphy, W. M. Getz, Trophic facilitation by introduced top predators: Gray wolf subsidies to scavengers in Yellowstone National Park. J. Anim. Ecol. 72, 909-916 (2003). doi: 10.1046/j.1365-2656.2003.00766.x

54. R. L. Beschta, R. J. Ripple, The role of large predators in maintaining riparian plant communities and river morphology. Geomorphology 157-158, 88-98 (2012). doi: 10.1016/j.geomorph.2011.04.042

55. D. W. Smith, D. B. Tyers, The history and current status and distribution of beavers in Yellowstone National Park. Northwest Sci. 86, 276-288 (2012). doi: 10.3955/046.086.0404

56. M. Hebblewhite, D. Smith, in The World of the Wolves: New Perspectives on Ecology, Behaviour, and Management, M. P. C. Musiani, P. C. Paquet, Eds. (Univ. of Calgary Press, Calgary, Alberta, Canada, 2010), pp. 69-120.

57. M. Hebblewhite et al., Human activity mediates a trophic cascade caused by wolves. Ecology 86, 2135-2144 (2005). doi: 10.1890/04-1269

58. C. Packer, R. D. Holt, P. J. Hudson, K. D. Lafferty, A. P. Dobson, Keeping the herds healthy and alert: Implications of predator control for infectious disease. Ecol. Lett. 6, 797-802 (2003). doi: 10.1046/ j.1461-0248.2003.00500.x

59. L. van Bommel, C. N. Johnson, Good dog! Using livestock guardian dogs to protect livestock from predators in Australia's extensive grazing systems. Wildlife Res. 39 220-229 (2012)

60. T. B. Muhly, M. Musiani, Livestock depredation by wolves and the ranching economy in the northwestern US. Ecol. Econ. 68, 2439-2450 (2009). doi: 10.1016/ j.ecolecon.2009.04.008

61. E. Nelson et al., Modeling multiple ecosystem services, biodiversity conservation, commodity production, and tradeoffs at landscape scales. Front. Ecol. Environ 7 4-11 (2009). doi: 10.1890/080023

62. R. L. Beschta, R. J. Ripple, Mexican wolves, elk, and aspen in Arizona: Is there a trophic cascade? For. Ecol. Manage 260, 915-922 (2010). doi: 10.1016/j.foreco.2010.06.012

63. W. ]. Ripple, R. L. Beschta, ]. K. Fortin, C. T. Robbins, Trophic cascades from wolves to grizzly bears in Yellowstone. J. Anim. Ecol. 83, 223-233 (2014). doi: 10.1111/1365-2656.12123; pmid: 24033136

64. T. Levi, C. C. Wilmers, Wolves-coyotes-foxes: A cascade among carnivores. Ecology 93, 921-929 (2012). doi: 10.1890/11-0165.1; pmid: 22690642

65. R. Callan, N. P. Nibbelink, T. P. Rooney, J. E. Wiedenhoeft, A. P. Wydeven, Recolonizing wolves trigger a trophic cascade in Wisconsin (USA). J. Ecol. 101, 837-845 (2013) doi: 10.1111/1365-2745.12095

66. C. Wikenros, thesis, Swedish University of Agricultural Sciences, Uppsala, Sweden (2011).

67. J. Berger, in Large Carnivores and the Conservation of Biodiversity, ]. Ray, K. H. Redford, R. Steneck, ]. Berger, Eds. (Island Press, Washington, DC, 2005), pp. 315-341.

68. W. J. Ripple, R. L. Beschta, Wolves and the ecology of fear: Can predation risk structure ecosystems? Bioscience 54, 755-766 (2004). doi: 10.1641/00063568(2004)054[0755:WATEOF]2.0.CO;2

69. L. M. Elbroch, H. U. Wittmer, Nuisance ecology: Do scavenging condors exact foraging costs on pumas in Patagonia? PLOS ONE 8, e53595 (2013). doi: 10.1371/ journal.pone.0053595; pmid: 23301093

70. S. H. Faeth, P. S. Warren, E. Shochat, W. A. Marussich, Trophic dynamics in urban communities. Bioscience 55, 399-407 (2005). doi: 10.1641/00063568(2005)055[0399:TDIUC]2.0.C0;2

71. P. Smith et al., How much land-based greenhouse gas mitigation can be achieved without compromising food security and environmental goals? Glob. Change Biol. 19, 2285-2302 (2013). doi: 10.1111/gcb.12160; pmid: 23505220

72. W. J. Ripple et al., Ruminants, climate change, and climate policy. Nat. Clim. Change 4, 2-5 (2014)

73. T. P. Dawson, S. T. Jackson, J. I. House, I. C. Prentice, G. M. Mace, Beyond predictions: Biodiversity conservation in a changing climate. Science 332, 53-58 (2011) doi: 10.1126/science.1200303; pmid: 21454781 
74. C. Parmesan, G. Yohe, A globally coherent fingerprint of climate change impacts across natural systems. Nature 421, 37-42 (2003). doi: 10.1038/nature01286; pmid: 12511946

75. C. Parmesan, Ecological and evolutionary responses to recent climate change. Annu. Rev. Ecol. Evol. Syst. 37, 637-669 (2006). doi: 10.1146/annurev.ecolsys. 37.091305 .110100

76. L. J. Gormezano, R. F. Rockwell, What to eat now? Shifts in polar bear diet during the ice-free season in western Hudson Bay. Ecol. Evol 3, 3509-3523 (2013). pmid: 24223286

77. C. C. Wilmers, W. M. Getz, Gray wolves as climate change buffers in Yellowstone. PLOS Biol. 3, e92 (2005). doi: 10.1371/journal.pbio.0030092; pmid: 15757363

78. R. S. Ostfeld, R. D. Holt, Are predators good for your health? Evaluating evidence for top-down regulation of zoonotic disease reservoirs. Front. Ecol. Environ 2, 13-20 (2004). doi: 10.1890/1540-9295(2004)002[0013: APGFYH]2.0.CO;2

79. T. Levi, A. M. Kilpatrick, M. Mangel, C. C. Wilmers, Deer, predators, and the emergence of Lyme disease. Proc. Natl. Acad. Sci. U.S.A. 109, 10942-10947 (2012). doi: 10.1073/pnas.1204536109; pmid: 22711825

80. R. M. Holdo et al., A disease-mediated trophic cascade in the Serengeti and its implications for ecosystem C. PLOS Biol. 7, e1000210 (2009). doi: 10.1371/journal.pbio. 1000210; pmid: 19787022

81. ]. A. Estes, ]. S. Brashares, M. E. Power, Predicting and detecting reciprocity between indirect ecological interactions and evolution. Am. Nat. 181, S76-S99 (2013). doi: 10.1086/668120; pmid: 23598361

82. D. F. Doak et al., Understanding and predicting ecological dynamics: Are major surprises inevitable? Ecology 89, 952-961 (2008). doi: 10.1890/07-0965.1; pmid: 18481520

83. ]. L. Gittleman, Carnivore body size: Ecological and taxonomic correlates. Oecologia 67, 540-554 (1985) doi: 10.1007/BF00790026
84. R. Woodroffe, S. Thirgood, A. Rabinowitz, People and Widlife. Conflict or Co-existence? (Cambridge Univ. Press, Cambridge, 2005).

85. J. L. Gittleman, S. M. Funk, D. MacDonald, R. K. Wayne, Carnivore Conservation (Cambridge Univ. Press, Cambridge, 2001).

86. Large Carnivores Initiative for Europe, http://www.lcie. org/Home.aspx; accessed 18 August 2013.

87. Global Tiger Initiative, http://globaltigerinitiative.org/; accessed 10 October 2013

88. World Bank, Minding the Stock: Bringing Public Policy to Bear on Livestock Sector Development (Report no. 44010-GLB, The World Bank, Washington, DC, 2009).

89. F. Sergio et al., Top predators as conservation tools: Ecological rationale, assumptions and efficacy. Annu. Rev. Ecol. Syst. 39, 1-19 (2008). doi: 10.1146/annurev. ecolsys.39.110707.173545

90. L. D. Mech, L. Boitani, Eds., Wolf-Prey Relations. Wolves: Behavior, Ecology, and Conservation (Univ. of Chicago Press, Chicago, 2003).

91. IUCN, The IUCN Red List of Species, Version 2012.2, http://www.iucnredlist.org; downloaded April 2013.

92. ]. A. Estes, D. O. Duggins, Sea otters and kelp forests in Alaska: Generality and variation in a community ecological paradigm. Ecol. Monogr. 65, 75-100 (1995). doi: $10.2307 / 2937159$

93. M. Letnic, F. Koch, Are dingoes a trophic regulator in arid Australia? A comparison of mammal communities on either side of the dingo fence. Austral Ecol. 35, 167-175 (2010). doi: 10.1111/j.1442-9993.2009.02022.x

94. W. J. Ripple, R. L. Beschta, Linking wolves to plants: Aldo Leopold on trophic cascades. Bioscience 55, 613-621 (2005). doi: 10.1641/0006-3568(2005)055[0613: LWAPAL]2.0.CO;2

95. R. L. Beschta, W. ]. Ripple, Wolves, trophic cascades, and rivers in the Olympic National Park, USA. Ecohydrology. 1, 118-130 (2008). doi: 10.1002/eco.12

96. P. J. White, K. M. Proffitt, T. O. Lemke, Changes in elk distribution and group sizes after wolf restoration.
Am. Midl. Nat. 167, 174-187 (2012), doi: 10.1674/ 0003-0031-167.1.174

97. K. M. Berger, E. M. Gese, Does interference competition with wolves limit the distribution and abundance of coyotes? J. Anim. Ecol. 76, 1075-1085 (2007). doi: 10.1111/j.1365-2656.2007.01287.x pmid: 17922704

98. K. M. Berger, E. M. Gese, ]. Berger, Indirect effects and traditional trophic cascades: A test involving wolves, coyotes, and pronghorn. Ecology 89, 818-828 (2008). doi: 10.1890/07-0193.1; pmid: 18459344

99. B. J. Miller, H. J. Harlow, T. S. Harlow, D. Biggins, W. ]. Ripple, Trophic cascades linking wolves (Canis lupus), coyotes (Canis latrans), and small mammals. Can. J. Zool. 90, 70-78 (2012). doi: 10.1139/z11-115

100. W. ]. Ripple, R. L. Beschta, Trophic cascades in Yellowstone: The first 15 years after wolf reintroduction. Biol. Conserv. 145, 205-213 (2012). doi: 10.1016 j.biocon.2011.11.005

101. L. M. Baril, A. J. Hansen, R. Renkin, R. Lawrence, Songbird response to increased willow (Salix spp.) growth in Yellowstone's northern range. Ecol. Appl. 21, 2283-2296 (2011). doi: 10.1890/10-0169.1; pmid: 21939061

102. F. A. O. Statistical Database, http://faostat.fao.org; accessed 12 August 2013.

103. H. Steinfeld, et al., Livestock's Long Shadow: Environmental Issues and Options (Food and Agriculture Organization of the United Nations, Rome, 2006).

Acknowledgments: We thank S. Arbogast, ]. Batchelor

A. Cloud, R. Comforto, A. Comstock, T. Newsome, L. Painter, L. Petracca, and C. Wolf for assisting in this project.

\section{Supplementary Materials}

www.sciencemag.org/content/343/6167/1241484/supp//DC1 Figs. $\mathrm{S} 1$ to $\mathrm{S} 4$

Tables S1 to S3

$10.1126 /$ science. 1241484 